\title{
Individual differences in power functions for a 1-week intersession interval*
}

\author{
WILLIAM ENGELAND and WILLIAM E. DAWSON* \\ University of Notre Dame, Notre Dame, Indiana 46556
}

\begin{abstract}
Two experiments examined correlations of the power function exponents of individual Ss obtained in each of two sessions. Half the Ss for any task performed second sessions immediately after the first, the other half after a week's delay. In Experiment $\mathbf{1}$, groups of $16 \mathrm{Ss}$ gave magnitude estimations of apparent area, or else of area and loudness. In Experiment II, groups of $16 \mathrm{Ss}$ made cross-modality matches of apparent time duration to area. Significant correlations in all cases indicated consistent and persisting $\mathbf{S}$ differences in exponents. The results are related to the findings of other studies of such individual differences.
\end{abstract}

There is evidence that the psychophysical power function may hold for the data of individual Ss as well as for group data. For example, close approximations to power functions have been found for individuals with the sensory continua of brightness (Marks \& Stevens, 1966), force of handgrip (Stevens \& Mack, 1959), loudness of white noise (Schneider \& Lane, 1963), loudness of a pure tone (Stevens \& Guirao, 1964), taste (Ekman \& Åkesson, 1965), and smell (Jones \& Marcus, 1961). However, these studies also demonstrated a considerable interindividual variability in the exponents of the power function for each continuum investigated. Luce (1972), pointing to this variability, has suggested that psychophysical measurement is fundamentally different from physical measurement.

Various researchers have suggested different possible causes for the variability in individual exponents. Purported causes include individual differences in judgmental criteria, in response bias, or in perceptual sensitivity, and reaction to situational variables, such as the number of repetitions of the stimuli in a session. Some of the investigators have contended that exponent variability reflects differences in judgmental processes, with different individuals adopting different quantitative criteria when they attempt to judge the relative magnitude of sensory impressions (Marks \& Stevens, 1966; Stevens \& Guirao, 1964). For them, Ss differ in what stimulus pairs are regarded as giving rise to any specific perceived ratio.

Rule (1966) reported data from a magnitude estimation task involving three different sensory continua in which correlations of individuals' exponents computed between continua were both positive and significant. Also, Rule and Markley (1971) showed that response factors influence judgments in scaling techniques other than magnitude estimation. Using both magnitude estimation (ME) and cross-modality matching (CMM) for three different continua, they found that

* R equests for reprints should be sent to William $\mathrm{E}$. Dawson, Department of Psychology, University of Notre Dame, Notre Dame, Indiana 46556. exponent correlations were highest between conditions with the same dependent variable. These correlations supported their hypothesis that $\mathbf{S}$ exhibits his own characteristic range of responses within a given response system; that is, differences in individual exponents were attributed largely to differences in response bias.

Ekman, Hosman, Lindman, Ljungberg, and Åkesson (1968) used a ratio estimation task to obtain individual sensory judgments for six different continua. Correlations based on ranges of individual judgments, for the various pairs of the six continua, were much smaller than estimates of reliability. From these findings, it was speculated that a large proportion of exponent variability might be accounted for by Ss' differences in sensory sensitivity or perceptual variability.

Unlike earlier researchers, Teghtsoonian and Teghtsoonian (1971) varied a secondary task variable, one not usually of primary concern in a scaling task. They varied the interval between scaling sessions to see if the significant correlations between individual exponents would occur for long intersession intervals. With ME of apparent area over successive experimental sessions, correlations between individual exponents across sessions were found to be positive and reliable only for an intersession interval of zero when care was taken to minimize intersession constraints. For six other intervals, ranging from 1 to 77 days, nonsignificant correlations were obtained. Therefore, they argued that the variability in individual exponents could not be attributed to any persisting sensory or judgmental differences. Teghtsoonian and Teghtsoonian speculated that repeated judging of stimuli might give rise to the correlations, and they suggested that two causes might be operative: (1) S's memory both for specific stimuli and responses to them, and (2) S's tendency to repeat previously made responses.

The present study also was concerned with the occurrence of correlations for a long intersession interval-1 week. It attempted to delineate further those conditions for which correlations occur as opposed to those for which they do not. Two different questions 
Table 1

Kendall Rank Correlations of Subjects' Exponents Across Two Sessions for Magnitude Estimation (Experiment I) and Cross-Modality Matching (Experiment II)

\begin{tabular}{|c|c|c|}
\hline & No Delay & Week Delay \\
\hline \multicolumn{3}{|l|}{ Magnitude Estimation } \\
\hline Area-Area & $.73^{* *}$ & $.58 * *$ \\
\hline Loudness-Area & $.45^{* *}$ & $.39 * *$ \\
\hline \multicolumn{3}{|l|}{ Cross-Modality Matching } \\
\hline Area-Area & $.33^{*}$ & $.62 * *$ \\
\hline
\end{tabular}

were investigated. First, what happens when two different continua, apparent area and loudness, are judged in the two sessions? The use of different stimuli would presumably rule out memory effects for specific stimuli and the responses to them, and consequently result in smaller correlations. We know from past research that individual differences occur when there is no delay between the sessions for two continua, but what about for a delay of 1 week? Secondly, what happens when CMM is substituted for the ME method used by Teghtsoonian and Teghtsoonian? Values produced in CMM may be anywhere along the continuum, and hence less easy to remember than the usual set of more familiar numbers emitted in ME. Do intersession correlations reach a nonsignificant level over time with CMM as Teghtsoonian and Teghtsoonian report they do for ME? Are they smaller than ME correlations? Again, correlations were compared for two intersession intervals: no delay and 1-week delay.

\section{EXPERIMENT I: MAGNITUDE ESTIMATION}

\section{Method}

Subjects. Ss were 64 undergraduates ( 10 females) enrolled in a course in introductory psychology at the University of Notre Dame. Each S received extra class credit for participation. All Ss in the delay condition, at the time of the first session, were aware that there would be a second session but not what task it would involve.

Apparatus Six circles were each drawn with black ink on a separate $5 \times 8$ in. white card. The areas of the circles were $4 \pi$, $12 \pi, 36 \pi, 108 \pi, 324 \pi$, and $972 \pi \mathrm{mm}^{2}$. The cards containing the circles were placed one at a time on the table at which $S$ was seated.

The 1,000-Hz tones, produced by an audio oscillator, were presented binaurally at sound-pressure levels of $40,50,60,70$, 80 , and $90 \mathrm{~dB}$ (re $0.0002 \mathrm{dyne} / \mathrm{cm}^{2}$ ). A key-operated switch enabled $S$ to listen to each tone through a pair of calibrated earphones.

Procedure. Magnitude estimation was employed to obtain subjective magnitude scales for both the apparent area of circles and the loudness of tones. For the first stimulus presented in each task, $S$ was instructed to give any number which seemed to him appropriate. For subsequent stimuli, $\mathrm{S}$ was to assign numbers in proportion to his sensory impressions. For the circle stimuli, S was explicitly told to judge apparent area and not to make judgments on the basis of what he knew about the geometry of circles. The aim here was to avoid judgments of actual, or physical, area (Teghtsoonian, 1965) as well as some linear measure of the circles such as diameter.
Each $S$ served in two sessions with the six values of a particular set of stimuli presented twice in a random order on each occasion. Half the Ss performed the ME of apparent area at both sessions. Of these Ss, one-half had no delay between sessions, while the others had a delay of 1 week between sessions. The remaining half of all Ss estimated apparent area at one session and apparent loudness at the other session. They were also divided into halves: one group had no delay between sessions, while the other group had a week's delay. Also, each of these groups was further divided, with one-half receiving circles first and the other half receiving tones first.

As a preexperiment familiarization procedure, each $S$ first judged a series of straight lines that varied in length. $S$ was instructed to give numbers in proportion to his impression of apparent length.

\section{Results}

Individual Ss' data from each session of ME were fitted by power functions. Averaged over groups and sessions, the mean exponents were .65 for area and .55 for loudness. Both of these values are within the range of exponents reported for these modalities in previous research, although both are slightly low. Power functions were found to be good descriptions of the data for individual Ss: the fits according to a criterion of least squares accounted for an average of $99 \%$ of the variance in the judgments.

Kendall rank correlations were computed for the individual exponents obtained from the first vs the second ME sessions. Rank correlations were used in place of product-moment correlations because differences in distributions of exponents for sessions were present across some of the conditions. These differences were in the dispersion and not in the shape of the distributions. The coefficients, presented in Table 1, were all found to be significantly different from zero. These correlations, indicating persisting individual differences in exponents, were higher when the continuum remained the same than when it changed, but not significantly so. In fact, there is no significant difference between any two of the correlations in Table 1, although correlations are smaller for the week-delay conditions.

Within-session reliability of individual exponents was also examined by calculating exponents both for the first judgments of each stimulus and then for the second judgment data. Kendall correlation coefficients (see Table 2) were computed for these exponents for each of the different sessions in the various conditions. The mean correlation was .67 , and all of the correlations were significant $(p<.01)$, indicating a high within-session reliability.

\section{EXPERIMENT II: CROSS-MODALITY MATCHING}

The failure to find nonsignificant correlations with a delay of a week in Experiment I led to modifications in procedure for Experiment II. Not only was the method changed to CMM, but also other conditions that may 
have contributed to the correlations in Experiment I were changed. Only one judgment instead of two, for any one stimulus, was required in a session-hence, the probability of remembering a previous stimulus-response pair presumably decreased. Thirteen, instead of six, stimuli were used to prevent absolute identification (Miller, 1956). The substitution of CMM for ME was intended to prevent $S$ from restricting himself to a subset of more familiar and rememberable responses, which is relatively easy when he is selecting numbers but more difficult on matching continua that contain fewer "landmarks."

\section{Method}

Subjects. Ss were 32 undergraduates ( 5 females) enrolled in an introductory psychology course at the University of Notre Dame. Thirteen of the Ss had taken part in Experiment I about 1 month earlier.

Apparatus. Thirteen circles were each drawn with black ink on an $81 / 2 \times 11$ in. sheet of paper. The areas of the circles ranged from 22.35 to $22,350 \mathrm{~mm}^{2}$ in equal ratio steps. A key-operated switch placed in series with an indicator light was used by Ss to match time duration to apparent area. A timer unit recorded the length of time that $S$ produced.

Procedure. All of the $S s$ adjusted time duration for a cross-modality match to their subjective impression of the apparent areas of circles. The circles were presented one at a time to each $S$ in a random order. For the first circle, $S$ was instructed to produce any time duration which seemed appropriate. Then, for the remaining circles, $S$ was to match time duration in proportion to the apparent areas of the circles presented to him. Each of the 13 circles was presented only once to each $S$ in a single session; each $S$ took part in two sessions. Half of the Ss had no delay between the two sessions, while the other half had a delay of 1 week between sessions.

\section{Results}

Although a different scaling procedure was used in this task, the data were treated in the same way as the data in Experiment I. Since the reported exponents (Stevens, 1961) for apparent area and time duration are .70 and 1.1 , respectively, the predicted slope for the match of duration to area is $.70 / 1.1$, or .64 . This value is appreciably larger than the value of .45 computed as the average exponent in the present experiment, but since apparent area was not in tum matched to apparent duration, the lower value may be due to the "regression effect" (Stevens \& Greenbaum, 1966). Again, the least-squares fit for individual data accounted for, on the average, $99 \%$ of the variance in the matches to apparent area. Kendall rank correlations computed between the individual exponents obtained from the first and second sessions were again significant, as shown in Table 1. Although the correlation for the week-delay group was larger than that of the no-delay group, the difference was not statistically significant.

\section{DISCUSSION}

Persisting individual differences in exponents were found in all of the situations examined by the two experiments. This reliability of individual exponents
Table 2

Within-Session Correlations (Tau) for Subjects' Exponents in Experiment I

\begin{tabular}{lcc}
\hline & $\begin{array}{c}\text { Session 1 } \\
\text { or Loudness }\end{array}$ & $\begin{array}{c}\text { Session 2 } \\
\text { or Area }\end{array}$ \\
\hline Area-Area & .56 & .82 \\
Area-Delay-Area & .62 & .53 \\
Loudness-Area & .75 & .70 \\
Loudness-Delay-Area & .64 & .75 \\
\hline
\end{tabular}

Note-All taus significant $(p<.01)$.

held both when the second session immediately followed the first session and when it followed it 1 week later. It also held in the second experiment with CMM in spite of the efforts to reduce the possible effects of previously made responses. Such findings support earlier work in indicating that a sizeable portion of the variation in the responses with direct scaling methods is attributable to differences in individuals.

Results for the no-delay groups are replications of previous studies. As in earlier research, significant correlations were found for (1) ME for the same continuum judged twice (cf. repeat reliability), (2) ME for two different continua, and (3) the reptition of CMM for the same continuum. The loudness-area correlation is smaller than the area-area one, a fact in line with Ekman et al, who found that reliability correlations are greater than those across continua. It was this finding that led them to suggest that more than just response bias underlies the individual differences. Note, for the present research, that the area-area no-delay correlation for Experiment I is of approximately the same magnitude as the within-session reliabilities in Table 2.

The week-delay groups provide new information about the persistence of individual differences in exponents over time. The area-area ME group, which received two repetitions per stimulus per session, gave persisting individual differences with a 1-week delay. This finding is for conditions somewhat different from those involved in the two experiments by Teghtsoonian and Teghtsoonian. In their first experiment, five sessions, each separated by $24 \mathrm{~h}$ with two repetitions per stimulus, resulted in significant correlations between adjacent sessions. A significant correlation was even found between the fifth session and a sixth session given 1 year later, but note here that Ss received five sessions before the lengthy year's delay. In comparison, the present area-area ME experiment is the first to show that two repetitions per stimulus are enough to yield a S's effect for up to a week's delay. In the second Teghtsoonian experiment, Ss gave MEs to area stimuli presented once per session and different groups of Ss received second sessions with different intersession intervals. These intervals varied from no delay up to 11 weeks, but a significant correlation was found only for the no-delay condition. The Pearson $r$ was approximately .4 for a 1 -week delay.

The significant correlation, with the delay, for the 
loudness-area ME group suggests that memory for specific responses made to specific stimuli is not the sole basis for persisting individual differences in exponents. Further, if there is a tendency for Ss to repeat certain responses, or a range of responses, then it appears to transfer from one stimulus continuum to another, with even up to a week's intersession interval.

The CMM delay group gave judgments under conditions that Teghtsoonian and Teghtsoonian suggest will reduce the effects of previously made responses upon subsequent ones. E, they say, "should let at least 1 day elapse between sessions and have $S$ judge a stimulus set only once per session." The CMM correlation, nevertheless, was still significant. But, it could be argued, Teghtsoonian and Teghtsoonian used only ME. Hence, if CMM gives higher intersession correlations than ME, then this might account for the present findings. However, Rule and Markley's data suggest that these correlations are of about the same magnitude, and so the CMM delay result would seem to conflict with the conclusions of Teghtsoonian and Teghtsoonian.

Other factors that could conceivably have affected the size of the CMM repeatability correlation include the stimulus range used, the number of Ss upon which the correlations are based, and the amount of prior related experience the Ss may have had. Both the CMM study and the second experiment of the Teghtsoonians used 1,000:1 stimulus ranges, and so this factor is not different for the two. Their study employed an average of $10 \mathrm{Ss}$, while the present data are based on 16 per condition. Thirteen of the 32 Ss in our Experiment II had taken part in Experiment I 1 month earlier, but otherwise they had had no experience in direct scaling tasks. The Teghtsoonians' article does not indicate their Ss' prior experience. If they were totally naive, this would be a difference that might account for the apparent difference in results. If true, then experience with ME would have had to affect subsequent CMM performance, an effect made less likely by Rule and Markley's finding that correlations are high for the same continuum matched to different stimulus continua, but low when two different continua are matched to the same stimulus continuum. In addition, the Teghtsoonian article states that the use of practiced Ss appears to lead to group exponents that are less affected by individual $\mathrm{S}$ effects.

Further research seems indicated to determine whether individual exponents arise from an ever-present response bias or a transitory memory effect. If it is a memory effect, then it should change with changes in variables known to affect memory, such as number of stimulus repetitions per session, the number of sessions, the time between sessions, and so forth. The present study does not rule out either of these effects; nor does it rule out differences in sensitivity or in judgment criteria. Possibly, all of these factors will be shown to have some effect in producing individual exponents.

\section{REFERENCES}

Ekman, G.. \& Åkesson, C. Saltness, sweetness, and preference: A study of quantitative relations in individual subjects. Scandinavian Journal of Psychology, 1965,6, 241-253.

Ekman, G., Hosman, B.. Lindman, R., Ljungberg, L., \& Akesson. C. Interindividual differences in scaling performance. Perceptual \& Motor Skills, 1968, 26, 815-823.

Jones, F. N., \& Marcus, M. J. The subject effect in judgments of subjective magnitude. Journal of Experimental Psychology, $1961,6,40-44$.

Luce, $R$. D. What sort of measurement is psychophysical measurem ent? American Psy chologist, 1972, 27, 96-106.

Marks, L., \& Stevens, J. C. Individual brightness functions. Perception \& Psychophysics, 1966, 1, 17-24.

Milier, G. A. The magical number seven, plus or minus two: Some limits on our capacity for processing information. Psychological Review, 1956, 63, 81-97.

Rule, $S$. Subject differences in exponents of psychophysical power functions. Perceptual \& Motor Skills, 1966, 23, $1125-1126$.

Rule, S., \& Markley, R. P. Subject differences in cross-modality matching. Perception \& Psychophysics, 1971, 9, $115-117$.

Schneider, B., \& Lane, H. Ratio scales, category scales, and variability in the production of loudness and softness. Journal of the Acoustical Society of America, 1963, 35, 1953-1961.

Stevens, J. C., \& Guirao, M. Individual loudness functions. Journal of the Acoustical Society of America, 1964, 36, 210-213.

Stevens. J. C.. \& Mack, J. D. Scales of apparent force. Journal of Experimental Psychology, 1959, 58, 405-413.

Stevens, S. S. The psychophysics of sensory function. In W. A. Rosenblith (Ed.), Sensory communication. Cambridge, Mass: M.I.T. Press, 1961.

Stevens, S. S., \& Greenbaum, H. B. Regression effect in psychophysical judgments. Perception \& Psychophysics, 1966 , 1, 439-446.

Teghtsoonian, M. The judgment of size. American Journal of Psychology, 1965, 78, 392-402.

Teghtsoonian, M., \& Teghtsoonian, R. How repeatable are Stevens's power law exponents for individual subjects? Perception \& Psychophysics, 1971, 10, 147-149.

(Received for publication March 16, 1973;

final revision received November 28,1973 .) 